\title{
SOLDADOS, DONCELLAS Y EXPÓSITOS: GONZALO DE CÉSPEDES Y MENESES, UN FIEL LECTOR CERVANTINO
}

\begin{abstract}
Entre la vasta pléyade de novelistas del siglo XvII, existen pocos que resistan una comparación con el Manco de Lepanto. No por falta de ingenio, sino por la sombra alargada del escritor alcalaíno. A veces olvidada, a veces mal entendida, la obra de Gonzalo de Céspedes no ha disfrutado de la atención que se merece. La prosa de ficción, un género que había quedado arrinconado por el triunfo rampante del teatro comercial, se había reinventado a sí misma gracias a las nuevas fórmulas narrativas que había dejado Cervantes como humus de lo que hoy en día conocemos como novela moderna. Se buscaba una profunda transformación estética en el romance; porque, en realidad, los renovadores de la narrativa -con el autor del Quijote a la cabeza- se concentraron en hacer suyo un principio de la Comedia Nueva, de especial importancia en géneros como el de capa y espada: dar voz a la realidad cotidiana. El espacio del hogar, los enredos amorosos, los conflictos de honra... atrajeron la atención del lector como antes lo habían hecho los mundos fantásticos de los libros de caballerías. Lo concreto, lo inmediato, lo intranscendente, que había obtenido el aplauso en los corrales, ahora se plasmaba como un universo real, al alcance de la mano del que estaba leyendo:
\end{abstract}

El romance levantaba ante los ojos de los lectores un universo maravilloso radicalmente distinto al de la realidad cotidiana, y, para que la ficción funcionase, exigía del receptor una permanente suspensión de su "experiencia" de la realidad... La novela -aunque, gracias al permanente diálogo que el texto de Cervantes acierta a mantener con el universo del romance, no elimina lo bizarro, lo raro, lo extraordinario- pretende referir una "experiencia" de lo real ${ }^{1}$.

${ }^{1}$ J. BLAsco, "Novela («mesa de trucos») y ejemplaridad («historia cabal y de fruto»)", en M. de Cervantes Novelas ejemplares, ed. J. García López, Crítica, Barcelona, 2001, pp. xii-xiii. En adelante, cito las Novelas ejemplares por esta edición. 
Los propios autores barrocos admitían las similitudes: "Demás que yo he pensado que tienen las novelas los mismos preceptos que las comedias", escribió Lope de Vega en sus Novelas a Marcia Leonarda ${ }^{2}$. La atención al mundo cotidiano no era el único lugar de encuentro entre el teatro y la novela. Como la Comedia Nueva, la narrativa estuvo en el centro de un intenso debate ético y estético sobre los peligros de la ficción, especialmente en individuos poco instruidos, aunque en el punto de mira no estaban sólo las mujeres y los niños, sino la sociedad en general. Como ya hiciera el Fénix para defender su fórmula teatral, Cervantes entró de lleno en la controversia para plantear una nueva escritura, a mitad de camino entre la fantasía de los libros de pastores o caballeros andantes - tan denostados por los moralistas-y la realidad de las novelle italianas -no menos repudiadas por su escasa vigilancia de las buenas costumbres. Desde un principio, el autor del Quijote rechazó la literatura devota porque la novela tenía que ser un juego, una "mesa de trucos", destinada a ocupar los ratos de ocio del lector. En medio del idealismo del romance, que representaba el "deber ser" de todas las cosas - una verdadera cosmovisión teórica-, y el realismo de la novella, identificado con el "ser" -es decir, una mirada práctica de su entorno-, se emplaza al hombre en un mundo que le resulta ajeno o extraño.

Como consecuencia inmediata, surge un conflicto entre el individuo y la realidad. La novela se convierte en un diálogo, llamémoslo así para satisfacer a cierta crítica, entre una verdad universal -poesía- que nunca se materializa y una verdad particular -historia- que arrastra a los personajes al fracaso, la decepción e incluso la muerte. Una lucha que genera un nuevo espacio para el género -ni real ni ideal-, donde el protagonista trata con ahínco de moldear la realidad a sus propios valores. Para Cervantes, el fin último no es vencer o salir derrotado, sino reconciliar al hombre con el mundo. Aquí radica la verdadera modernidad del Príncipe de los Ingenios. Los personajes cervantinos se caracterizan por su voluntad firme de "querer ser", de enfrentarse a una sociedad con la que parecen estar inmersos en un conflicto permanente. Don Quijote quiere ser un caballero andante y Sancho gobernador. La psicología de cada uno de ellos no sólo se individualiza con sus propios deseos y temores, sino que evoluciona según avanza su relación con el medio ${ }^{3}$. El Alonso Quijano de la primera página se asemeja muy poco al de la última. En la novela cer-

${ }^{2}$ Ed. A. Carreño, Cátedra, Madrid, 2002, p. 183.

${ }^{3}$ El perfil psicológico ya no se adecua a las exigencias de una clase determinada. Finalmente, con Cervantes desaparece por completo la categorización y el concepto de arquetipo literario. Tal individualidad ocasiona que las voces se multipliquen y, por consiguiente, las perspectivas con las que se afrontan los hechos. El mismo suceso juzgado de diferentes maneras: "Mediante una especie de proceso de refracción, añade a la novela -o crea la ilusión de añadirle- una dimensión más. Anuncia esa técnica de los novelistas modernos mediante la cual la acción se contempla a través 
vantina, el proceso de madurez de los personajes, que antes hemos llamado reconciliación, debe consumarse en una doble vertiente: primero, desde un punto de vista interno, con la armonización de sus valores a la realidad mundana -por ejemplo, sin dejar El Quijote, al final, el hidalgo se reconcilia con el caballero andante-; y segundo, de manera externa mediante un entendimiento entre el protagonista y el resto de personajes, cuyas acciones tendrán un impacto determinante en su evolución psicológica ${ }^{4}$.

Este camino hacia la modernidad es el mismo que se adivina en la obra del talaverano Gonzalo de Céspedes y Meneses ${ }^{5}$ y, más concretamente, en su Varia fortuna del soldado Píndaro (1626) ${ }^{6}$. No nos referimos a una posible influencia del Quijote, cuya recepción en la época barroca ha sido suficientemente tratada por otros, sino al papel de las Novelas ejemplares (1613) como fuente primaria para la redacción de su obra ${ }^{7}$. En particular, nos referimos a una serie de similitudes o coincidencias a nuestro juicio reveladoras, que probarían no sólo que Céspedes y Meneses leyó la colección de novelas cervantinas, sino

de los ojos de uno o más de los personajes en ella implicados" (E. Riley, Teoría de la novela en Cervantes, Taurus, Madrid, 1971, pp. 71-72).

${ }^{4}$ Quizás el paradigma más llamativo de influencia de un personaje sobre otro sea el de El amante liberal, donde Leonisa, movida por los sacrificios de Ricardo, a pesar de que nunca había correspondido a su amor, decide elegirlo a él como marido en vez de a su querido Cornelio. Al final, Cervantes nos deja decidir quién es el auténtico "amante liberal”: “-Pues con esa licencia -prosiguió la discreta Leonisa-, quiero que no se me haga de mal mostrarme desenvuelta, a trueque de no mostrarme desagradecida; y así, ¡oh, valiente Ricardo!, mi voluntad, hasta aquí recatada, perpleja y dudosa, se declara a favor tuyo; porque sepan los hombres que no todas las mujeres son ingratas, mostrándome yo siquiera agradecida. Tuya soy, Ricardo, y tuya seré hasta la muerte" (Novelas ejemplares, p. 158).

${ }^{5}$ Durante años se había creído que Céspedes y Meneses era de origen madrileño, pero investigaciones recientes han demostrado que fue en Talavera de la Reina donde nació el novelista (A. MAdroñal Durán, "Sobre el autobiografismo en las novelas de Gonzalo de Céspedes y Meneses a la luz de nuevos documentos”, Criticón, 51, 1991, pp. 100-101).

${ }^{6}$ La primera y única edición que salió a la calle en vida del autor fue la publicada en Lisboa por Geraldo de la Viña. Todavía en el siglo XVII, ya fallecido, aparecieron tres tiradas más: Vicente Álvarez, Lisboa, 1640; Melchor Sánchez, Madrid, 1661, y Pascual Bueno, Zaragoza, 1696.

${ }^{7}$ GeOrge Hainsworth ya apuntó brevemente el ascendente de la colección de relatos cervantinos en otra obra del escritor talaverano, las Historias peregrinas y ejemplares: "les deux récits [El buen celo premiado y Pachecos y Palomeques] nous venons d'analyser sont, comme nous l'avons dit, tout à fait représentatifs de la manière de Céspedes y Meneses. Complexes et pleines d'incidents, à la façon de la comedia, ces historias peregrinas ont pour ressorts, comme elle, l'amour, la jalousie et l'honneur. Elles rappellent ainsi exactament la Señora Cornelia et les Dos doncellas de Cervantes, et l'on peut dire que Céspedes y Meneses, en s'appropriant la formule de Cervantes, l'a menée presque à la perfection" (Les "Novelas exemplares" de Cervantes en France au XVII ${ }^{e}$ siècle: contribution à l'étude de la nouvelle en France, Ayer Publishing, New York, 1971, p. 160). 
que además se basó en tres de ellas -El casamiento engañoso, Las dos doncellas y La señora Cornelia- para la composición de ciertos episodios.

Entendiendo el contexto, tampoco lo podríamos considerar como un caso aislado. El éxito del Quijote fue inmediato ${ }^{8}$. La experimentación cervantina tuvo una fértil influencia en toda una generación de autores barrocos que continuaron la senda trazada. Aquellas fórmulas narrativas no sólo se convirtieron en el marco de una revolución formal - "Precisamente, muchas de las sorpresas que debe haber deparado el texto cervantino en el momento de su aparición estaban estrechamente unidas a la modernidad expresiva de su discurso" sino también en el fundamento de una serie de cambios sustanciales en temas, motivos, personajes, argumentos, y así un largo etcétera. Todo un rejuvenecimiento para un género que todavía andaba "en construcción” -según Anthony Close- cuando Cervantes compuso sus Novelas ejemplares.

\section{LA VARIA FORTUNA DEL SOLDADO PÍNDARO:} ¿UNA NOVELA INCLASIFICABLE?

Es de sobra conocido que una buena parte de la producción literaria de Céspedes y Meneses pasa por ser autobiográfica o cuando menos inspirada en experiencias personales, aunque el autor se preocupara de encubrir ciertos detalles por prudencia: "Ninguna cosa é permitido se le quite al verdadero original; sólo en algunos nombres, materias rígidas y circunstancias mal digestas mudé lo conveniente al estado que corre" ${ }^{10}$. Por desgracia, la opacidad de su biografía imposibilita la verificación de gran parte de los episodios narrados - por no decir prácticamente todos. Sin duda, el autor se

8 "Se sabe que el Quijote, sobre todo el personaje de Don Quijote y el de su fiel escudero, llegaron a ser rapidísimamente célebres, en España y fuera de ella: ya antes de la publicación de la Segunda parte Don Quijote era popularísimo. Apareció en un desfile de Valladolid en junio de 1605; el licenciado Francisco Márquez Torres en su aprobación puesta al frente de la Segunda parte, de febrero de 1615, asegura que los escritos de Cervantes habían sido recibidos «con general aplauso» en España, Francia, Italia, Alemania y Flandes; no sólo la primera parte del Quijote, sino La Galatea y las Novelas eran estimadas «así en Francia como en los reinos confinantes»" (F. MEREgALLI, "Los primeros dos siglos de recepción de la obra cervantina: una perspectiva", en Actas del III Coloquio Internacional de la Asociación de Cervantistas [Alcalá de Henares, 12-16 de noviembre de 1990], Anthropos, Madrid, 1993, p. 34). Para saber más sobre la recepción de la obra cervantina en pleno siglo xviI, véase el breve capítulo que le dedica J. Montero Reguera en su libro El Quijote durante cuatro siglos. Lecturas y lectores, Universidad, Valladolid, 2005 , pp. 15-26.

${ }^{9}$ I. Lerner, "Contribución al estudio de la recepción del Quijote", en Actas del III Coloquio Internacional..., p. 23.

${ }^{10}$ G. DE CÉspedes y Meneses, Varia fortuna del soldado Píndaro, ed. A. Pacheco, Espasa-Calpe, Madrid, 1975, t. 1, p. 24 (cito por esta edición). 
esfuerza por hacernos creer que nos está contando sucesos acaecidos durante unos años determinados, pero el trasunto de la acción cambia de manos muy pronto, pasando del "autor-narrador" 11 a uno de los personajes: un soldado de nombre Píndaro. Este cambio de narradores, al que ya volveremos más adelante, no nos debe llevar a engaño. El plan permanece invariable. Sigue siendo aquel "autornarrador" de la primera página quien nos está contando la historia de su vida, aunque no siempre empleará al soldado según para cuál aventura $^{12}$.

Un relato autobiográfico como éste nos llevaría a pensar en una novela picaresca, pero lo cierto es que no comparte muchas más de las características del género. A lo mejor -tal y como apunta Núñez Rivera-, se trataría de unas memorias de soldado, cuya tradición se remontaba al siglo anterior, pero en realidad Píndaro rara vez ejerce como tal. Ni siquiera podríamos hablar de literatura militar. En ningún momento se nos cuenta un episodio bélico de importancia. Dejando a un lado la camaradería que se granjea con algunos veteranos holgazanes en el Patio de los Naranjos hispalense, apenas tenemos pruebas o noticias de su condición de soldado, salvo cuando elige pasearse con las galas propias de la milicia ${ }^{13}$. Su única hazaña guerrera es cuando decide embarcarse para Italia con plaza de soldado y se encuentra por casualidad con unos corsarios berberiscos. La primera parte acaba cuando decide pasar a Flandes, pero al comienzo de la segunda ya ha regresado, por lo que nada sabemos sobre su suerte en la guerra ${ }^{14}$.

${ }^{11}$ Por "autor-narrador" entendemos el narrador homodiegético, exterior o interior, del que nos habla C. SEgRe en Principios de análisis del texto literario, Crítica, Barcelona, 1985, p. 31.

12 "Diríase que hay en la novela un doble desdoblamiento de la personalidad del autor, y que éste confía a don Francisco de Silva la tarea de presentar aquellas acciones excesivamente comprometedoras que no podía confesar su quizá demasiado claro disfraz de soldado Píndaro" (Varia fortuna, t. 1, p. 31).

13 "Y en el ínterin, como si ya lo fuéssemos, con colores y plumas y licenciosas galas de soldados, hizimos más de dos travesuras. Desplegamos las ojas, y aun las manos, con tan buena fortuna que, en dos días, sin tres pelos de barva, se nos dava lugar en el Corral de los naranjos, digo, entre los oficiales de la muerte, ministros del dios Marte" (ibid., t. 1, p. 139).

14 “...el uno aspiró a algún govierno, el otro, que fui yo, se encaminó a adquirir una ventaja para Flandes... Y con todo, no obstante las ayudas que tuve, passaron muchos meses antes de efectuarse mi intento, y juntamente en su dilación, por mi persona notables y peregrinas aventuras; pero en particular es la una dellas mui digna de ponerse en la estampa; si bien quiero primero, con breve intercadencia, dar alivio a mi pluma, concluyendo este libro, para que en el segundo nueva fuerça y historia le den mejor principio... Andava yo a este tiempo por Valladolid con licenciosas galas de soldado señalado y luzido, ya unas vezes pintado de diversas colores, y ya otras con los estremos dellas, plumas, guarniciones y bandas, y ya con más cadenas, cintillos y botones que muestra una fachada de platero" (ibid., t. 1, p. 222 y t. 2, p. 10). 
Por lo tanto, se trataría de un texto híbrido, donde hallamos trazas de la picaresca, técnicas de la novela sentimental -el amor epistolar de don Gutierre y Hortensia ${ }^{15}$ - y argumentos de la narrativa bizantina -naufragios, prisiones, juicios, etc. ${ }^{16}$. Sin desdeñar que, quizás, la Varia fortuna sea también una novela cortesana ${ }^{17}$ a la manera tal cual la interpreta Jenaro Talens: "el de ser resultado de lo que Hauser definió como «cultura autoritaria de la corte»"18. Nuestra novela admitiría todas estas hipótesis y ninguna:

En cuanto al modelo discursivo, se trata de una vida o memorias de soldado y acusa, por tanto, una vinculación con la picaresca, a causa de la narración autobiográfica. Pero su estructura narrativa resulta más propia del género bizantino, como el Español Gerardo... Esa estructura se implementa con una colección de relatos intercalados, aventuras fundamentalmente amorosas, aunque también se inserten episodios más relacionados con la Historia. Genéricamente pertenecen al modelo de la novela corta, como las Historias peregrinas ${ }^{19}$.

${ }^{15}$ Ya hace tiempo J.M. Osma descubrió la presencia de la novela Historia de duobus amantibus de Piccolomini en la Varia fortuna ("Sobre un caso de amores de la novela Varia fortuna del soldado Píndaro de D. Gonzalo de Céspedes y Meneses", $H$, 7, 1924, 368-376). I. RAVASINI editó como tesis doctoral una traducción castellana anónima del siglo xv (E. Silvio Piccolomini, Estoria muy verdadera de dos amantes, Bagatto Libri, Roma, 2004), de la que salió un interesante artículo sobre el tema ("Percorsi intertestuali tra citazione e rifacimiento: dalla Historia de duobus amantibus di Enea Silvio Piccolomini alla Varia fortuna del soldado Píndaro di Gonzalo Céspedes y Meneses", Annali della Facoltà di Lingue e Letterature Straniere [Bari], 12, 1995-98, 45-57).

${ }^{16}$ La admiración de Céspedes y Meneses por los modelos canónicos de la novela griega (Heliodoro y Aquiles Tacio) se remontaba varios años atrás, a una traducción de Leucipe y Clitofonte, como nos recuerda L. CuCALA Benítez: "Y es que nuestro autor [Céspedes y Meneses] escribió un soneto para la traducción que Diego de Ágreda y Vargas hizo de la obra de Aquiles Tacio con el título de Los más fieles amantes Leucipe y Clitophonte en 1617. En este poema elogioso Céspedes destaca la importancia de la recuperación de la obra de Aquiles Tacio: «de original que admiró tanto, / vuestro traslado, dignamente, / hoy triunfa superior, vence su olvido" "“Céspedes y Meneses y la novela griega: la providencia en el Español Gerardo y en las Etiópicas", Etiópicas, 2, 2006, p. 347).

17 "La preocupación por el valor y significado del dinero y el interés resultante caracterizan la sociedad barroca y son prioritarias en el debate de Céspedes. Pero su posición es ambigua. Sus novelas se erigen como un espacio de discusión y lucha en relación a la posición ideológica de la nobleza urbana" (N. Romero-Díaz, Nueva nobleza, nueva novela: reescribiendo la cultura urbana del barroco, J. de la Cuesta, Newark, 2002, p. 61).

${ }^{18}$ J. TAlens, "Contexto literario y real socializado. El problema del marco narrativo en la novela corta castellana del Seiscientos", en La escritura como teatralidad, Universidad, Valencia, 1977, p. 181.

${ }^{19}$ V. Núñez Rivera, "Un avatar tardío de la ficción sentimental. Céspedes y Meneses recrea a Piccolomini", en El Siglo de Oro en escena. Homenaje a Marc Vitse, PUM-Consejería de Educación de la Embajada de España en Francia, Toulouse, 2006, p. 641. 
En definitiva, sería un ejercicio práctico de experimentación a la manera barroca, que, como veremos un poco más adelante, tenía un ojo puesto en los escritos cervantinos. No debe sorprender demasiado, ya que en el siglo Xvi se comienza de manera incipiente a eliminar las fronteras entre géneros, especialmente entre comedia y novela, por lo que la Varia fortuna habría que entenderla más como un producto de su tiempo que como una unión imperfecta de diversos tipos narrativos.

\section{Prólogo Al LEGTOR: EN BUSGA DE LA EJEMPLARIDAD CERVANTINA}

Para constatar la admiración que debió sentir Céspedes y Meneses por el escritor alcalaíno bastaría recordar que a su colección de novelas le puso un nombre de evidentes reminiscencias cervantinas: Historias peregrinas y ejemplares (1623). Y advertido queda que no estamos aceptando 'ejemplar' con una significación ética, como sucede con cierta crítica ${ }^{20}$. En ninguno de los dos autores podríamos entender el concepto de 'ejemplaridad' como una calificación moral, sino como el primero de muchos ${ }^{21}$, es decir, una 'novedad': "Esta evolución de técnica y estilo [en la Varia fortuna], menos artificioso y culto, nos muestra un Céspedes y Meneses consciente de su arte y a la busca de un género original" ${ }^{22}$. La búsqueda de la originalidad, es decir, la voluntad expresa de celebrar su obra por encima del resto, separándola de cualquier modelo o paradigma anterior, antiguo o moderno, está muy presente en ambos autores. Todos recordamos las famosas líneas del prólogo a las Novelas ejemplares: “...y es así, que yo soy el primero que ha novelado en lengua castellana..." (Novelas ejemplares, p. 19). En la Varia fortuna, Céspedes y Meneses se disculpa por el uso de una retórica prestada "gracias a polianteas, brocárdicos, proverbios y lugares comunes" (Varia fortuna, t. 1, p. 10), pero advierte que todo lo demás es cosecha propia: "En quanto a estas alajas, yo te confiesso el robo; sólo lo enxerto y la invectiva es mío".

Como nota al margen, todavía en el prólogo, existe una clara intención de seguir los pasos de Cervantes. En las primeras líneas, el talaverano recurre exactamente a la misma versión del tópico de la captatio benevolentiae que advertimos a la cabeza de las Novelas ejempla-

${ }^{20}$ Aclarado esto, tampoco habría que cerrarse a una interpretación unívoca del término 'ejemplar', visto el autor y el contexto. En aquellos tiempos, era necesario hacer hincapié en que se podía sacar buen provecho de la lectura de aquellas novelas. La mala fama de la novella italiana, con la que se asociaba inmediatamente estos relatos breves de ambiente urbano, hacía aconsejable poner tierra de por medio por motivos éticos, estéticos y, por qué no, comerciales.

21 ejemplar: "original, prototipo, norma representativa" (DRAE).

${ }^{22}$ G. DE CÉspedes y Meneses, Historias peregrinas y ejemplares, ed. Y.-R. Fonquerne, Castalia, Madrid, 1980, p. 38. 
res: "Quisiera yo, si fuera posible, lector amantísimo, excusarme de escribir este prólogo, porque no me fue tan bien con el que puse en mi Don Quijote, que quedase con gana de segundar con éste" (Novelas ejemplares, p. 15). En la Varia fortuna, leemos la misma pro forma, la disculpa por no haber evitado "molestar" al lector con un prólogo:

Aunque pudiera con la introducción que hago en el principio del Soldado escusarte, o letor, del presente prólogo, todavía é querido antes -escribámoslo assí- duplicar esta actión que, singularizándome, faltar al uso inmemorial y a la costumbre recebida (Varia fortuna, t. 1, p. 9).

A partir de aquí, poco más tienen en común, es verdad, pero lo que también es palpable es que ambos comparten un fin último, el de proclamar lo nuevo de su narrativa, la originalidad de su creación, lo novedoso de su literatura. Sólo a través de esta conciencia de autoría se puede entender la novela barroca española, con Céspedes y Meneses entre otros, que dio lugar a lo que hoy llamamos "novela moderna”.

\section{APRENDIENDO A ESCRIBIR: EL CASAMIENTO ENGAÑOSO}

En el Siglo de Oro todavía existía el convencimiento de que todo texto escrito describía la realidad. Leer era creer y por ahí se sustentaban los ataques de los moralistas ${ }^{23}$. Como ya hemos señalado, el autor del Quijote entró al trapo de la polémica sobre los peligros de la ficción, aunque bien es cierto que lo hizo a su manera, sin artes ni discursos, sacando su "mesa de trucos" y comprobando hasta qué punto se podía manipular la mente del lector ${ }^{24}$. Para demostrar la capacidad de artificio de un buen novelista, decidió diluir la frontera entre la realidad y la ficción, entre verdad o verosimilitud; en definitiva, entre el lector y el texto literario. Y de la manera más difícil posible: asegurándonos que los perros hablan. Para semejante empresa levantará una estructura algo complicada, aunque no tanto para Céspedes y Meneses, pues se valdrá de ella en su Varia fortuna y con el mismo propósito: crear una falsa ilusión de verdad, tal y como el alférez

23 "Hoy en día, cuando dentro del contexto de la literatura de creación hablamos de creer, nos referimos a dos clases distintas de creencias, una racional y otra estética. Para los lectores y críticos del siglo xvi, esta distinción no estaba clara. Don Quijote no era de ningún modo el único lector español del Siglo de Oro que se creía todo lo que leía en los libros... Melchor Cano cuenta la historia de un sacerdote que se negaba a aceptar que algo que estuviese impreso pudiese ser falso, actitud satirizada por Lope de Vega y Cervantes" (B.W. Ife, Lectura y ficción en el Siglo de Oro. Las razones de la picaresca, Crítica, Barcelona, 1992, pp. 35-36).

${ }^{24}$ Para comprender a fondo la estructura de El casamiento engañoso y El coloquio de los perros se nos antojan como fundamentales las páginas de B.W. IFE (ibid., pp. 39-44). 
Campuzano se esfuerza por convencer a su amigo el licenciado de que escuchó una conversación entre canes.

Toda autobiografía -y la novela de Céspedes y Meneses pasa por tal- precisa de credibilidad. El autor debe hacer creer al lector que todos aquellos sucesos ocurrieron en realidad, es decir, que son historia y no poesía ${ }^{25}$. Por lo tanto, requiere que no haya barreras entre el lector y el texto; en una palabra, necesita convertirlo en parte de la fábula. Cervantes le enseñó el camino: eliminar cualquier intromisión del autor. En El casamiento engañoso, el doliente Campuzano no intenta persuadir a su amigo con discursos o argumentos ${ }^{26}$, le da a leer el coloquio que consiguió anotar y le invita a leerlo en silencio, mientras él se echa a dormir una siesta. Ya no queda nada -ni narrador ni personajes- entre Peralta y el lector. El licenciado está haciendo lo mismo que nosotros, una lectura callada, íntima y personal. Como cualquier otro lector, recrea el diálogo canino en el interior de su propia cabeza, transformándose en cierto modo en su autor. Por ende, Cervantes logra que los juicios, pensamientos y valoraciones de Peralta sean también los nuestros y que creamos o rechacemos lo mismo que el licenciado. Al tejer este espacio íntimo que une al lector con el texto, estamos a su merced. Puede manipular a su antojo nuestra capacidad de raciocinio, incluso convencernos de que verosimilitud es igual a verdad, por increíble que parezca: "Sólo así pueden Cervantes y Campuzano culminar el juego de manos por el que la verosimilitud de lo que los perros presuntamente dijeron se usa como garantía de que éstos realmente hablaron" (ibid., p. 42).

Para conseguir el mismo efecto en su Varia fortuna, Céspedes y Meneses trasladará paso a paso la estructura cervantina: un soldado convaleciente -Píndaro/Campuzano-, obligado por la amistad que se ha granjeado con su compañero de encierro - el "autor-narrador" / Peralta-, se presta a contar su vida, pero no lo hace de palabra, sino por escrito, sacando de un baúl "dos legajos en forma de quadernos" (Varia fortuna, t. 1, p. 23) escritos de su puño y letra "según los successos y vida del Soldado. La qual él mismo escrivió en la siguiente forma..." (ibid., t. 1, p. 24). Y para salvar el último escollo entre el lector

${ }^{25}$ En aquella época, la confusión entre géneros y el rechazo a la ficción provocan un acercamiento entre novela e historia. Ya en el siglo Xvi se había comenzado a escribir una ficción con pretensiones de historia, con la práctica de enmarcar cronológicamente los relatos, poner en imprenta hechos reales, historias apócrifas, etc. Asimismo, el gusto de la novela por lo cotidiano, es decir, por los sucesos particulares, apoyó sin duda esta tendencia, que también se vio reforzada del otro lado, pues se advierte una "novelización" de la historia de la que, por cierto, Céspedes y Meneses es un buen ejemplo por sus obras históricas.

${ }^{26}$ La experimentación cervantina demostró a Céspedes y Meneses la imposibilidad del texto de validarse por sí mismo. Prometer que los hechos sucedieron de verdad no es suficiente. La constatación de que un texto habla de la realidad ya sólo puede hacerla el lector. Por lo tanto, la perspectiva ha cambiado, puesto que ya no es un fenómeno de escritura, sino de lectura. 
y el texto, al igual que hiciera Cervantes, retira a un lado el personaje del soldado, dejando solo al "autor-narrador" con su lectura:

Essos fragmentos son progresos de mi vida y el mejor desempeño de mi palabra. Vedlos y corregidlos, pues para todo ay tiempo en vuestra reclusión y mi convalencia, y si ya os parecieren dignos de publicarse, vuestro consejo será su execución; dellos y de su dueño podréis hazer lo que por bien tuviéredes (ibid., t. 1, p. 23).

Ahora bien, el juego que se nos plantea en El casamiento engañoso y El coloquio de los perros esconde debajo una reflexión magistral sobre la naturaleza del acto de leer. Para Cervantes, la lectura está necesitada a la vez de una implicación por parte del lector -para creer en la verdad fingida de la fábula- y de un distanciamiento crítico -donde acaba el texto, comienza la vida real $^{27}$. El peligro de la ficción no reside en el libro en sí, sino en el propio lector -don Quijote es el mejor ejemplo-, que no debe olvidar que toda novela es un juego en el que se habla de la realidad desde la ficción, "donde cada uno pueda llegar a entretenerse, sin daño de barras; digo, sin daño del alma ni del cuerpo" (Novelas ejemplares, p. 18). Algo de lo que también nos advierte Céspedes y Meneses en su Varia fortuna. Verdad o ficción, realidad o fantasía, a la letra impresa siempre hay que juzgarla desde la curiosidad y la severidad -participación/distanciamiento cervantino-, porque ningún lenguaje escrito es capaz de traducir la realidad, sólo reflejarla como una especie de espejo del mundo:

En este respeto justo los á puesto en la estampa, de adonde salen hoy a que la curiosidad los admire y la severidad los censure y enmiende; y por lo menos ésta, siendo siempre deudora a mi buen desseo, no le podrá negar el metal rudo y pobre que con tales discursos ofrece a sus martillos cada día, ni aquélla la entretenida variedad con que procura divertirla y grangearla (Varia fortuna, t. 1, pp. 23-24).

Será este juicio crítico, "la severidad los censure y enmiende", al que se refería Cervantes cuando en el prólogo de las Novelas ejemplares invitaba al lector a no "hacer pepitoria, porque no tienen pies, ni cabeza, ni entrañas, ni cosa que les parezca" (Novelas ejemplares, pp. 17-18). Tanto Cervantes como Céspedes y Meneses nos están advirtiendo de que la ficción no enseña al lector a relacionarse con la realidad, a ser mejor ciudadano u hombre de Dios. Los libros se leen, pero no se viven.

27 "La forma de ficción que persigue Cervantes tiene una doble cara: la acción que refiere es mentira, en cuanto que... carece de correlato en la vida real... pero la acción referida es verdad, en cuanto que tiene la capacidad de «refertur ad aliquam significationem» de la realidad" (J. Blasco, "Novela [«mesa de trucos»]...", en Novelas ejemplares, p. xxviiii). 
Otro episodio de la Varia fortuna donde advertimos una huella cervantina se enmarca en el capítulo 19, aunque su origen real habría que buscarlo algo más atrás. Hospedado en un mesón de Sanlúcar junto a su amigo don Francisco, Píndaro escucha de noche un llanto desconocido que proviene del otro lado de la pared:

...quedándome en la cama solo... oí, no sin muy grande espanto y alteración de mi espíritu, como de rato en rato lloravan y gemían cerca de mi cabeça... Sentéme sobre el lecho, ensanché el coraçón y alargué las orejas... y al fin, bien satisfecho, caí en que procedía de otro [aposento], pared en medio, y con quien alindavan unos flacos tabiques (Varia fortuna, t. 1, pp. 182-183).

Un preludio tan secreto para otra de las aventuras de nuestra novela recuerda demasiado al mesón de Castilblanco donde se inicia la narración de Las dos doncellas, aunque sin pared de por medio:

...a poco más de la media noche comenzó a suspirar tan amargamente que con cada suspiro parecía despedírsele el alma; y fue de tal manera que, aunque el segundo [huésped] dormía, hubo de despertar del lastimero son del que se quejaba. Y admirado de los sollozos con que acompañaba los suspiros, atentamente se puso a escuchar lo que al parecer entre sí murmuraba (Novelas ejemplares, p. 445).

El paralelismo salta a la vista inmediatamente. Los dos huéspedes misteriosos tienen muchos rasgos en común: al principio nadie conoce identidad -ni siquiera su sexo-, viven encerrados en sus aposentos y, después de algunas pesquisas, resultan ser mujeres abandonadas. Las damas, otrora doncellas, van en busca de sus amantes, que han desaparecido después de gozarlas bajo promesa de matrimonio. En ambos casos, su situación desesperada incita la compasión de los protagonistas, que les prometen ayuda, pero antes suplican saber la historia:

...regalada y servida de nuestras flacas fuerças, acariciada del hospedage en que la agasajamos, y ofreciéndola con muy sanas entrañas su remedio y nuestra ayuda, la convencimos y obligamos a que nos diesse cuenta de las desdichas que continuo llorava (Varia fortuna, t. 1, pp. 186-187).

...y si esta compasión que os tengo y el presupuesto que en mí ha nacido de poner mi vida por vuestro remedio, si es que vuestro mal le tiene, merece alguna cortesía en recompensa, ruégoos que la uséis conmigo, declarándome, sin encubrirme cosa, la causa de vuestro dolor (Novelas ejemplares, p. 446). 
La búsqueda de los esposos ${ }^{28}$ acaba de manera diferente según el autor, como es por todos conocido, aunque tanto en la Varia fortuna como en Las dos doncellas las mujeres esconden la misma sorpresa: ya conocían a sus bienhechores -aunque ni ellas se dan cuenta hasta más adelante. En la novela de Céspedes y Meneses es Elvira, la misma dama sevillana que entregó a Píndaro un cofre en mitad de la noche confundiéndolo con su amante (Varia fortuna, t. 1, p. 143); mientras que en el relato cervantino, Teodosia, que así se llama, sin saberlo le está confesando su deshonra a su propio hermano (Novelas ejemplares, p. 451). De nuevo, el talaverano sigue los mismos parámetros estructurales que Cervantes, en concreto, los de las Novelas ejemplares, para la composición de su obra.

\section{LA PRUEBA VIVA DE LA INFAMIA: LA SEÑORA CORNELIA}

El motivo literario del niño abandonado al poco tiempo de nacer es tan antiguo como la propia literatura. Sin ir más lejos, en la Biblia tenemos el paradigma más famoso de todos: Moisés. Empero no sólo la religión o la historia, la mitología universal está llena de hombres, héroes y dioses expósitos, a los que el destino les reservaba grandes proezas. Por lo tanto, atribuir la paternidad de dicho motivo a Cervantes o a Céspedes y Meneses sería un tanto precipitado. Además, como cualquier otro mito, descansa sobre un fondo real.

En nuestro Siglo de Oro, era una práctica más frecuente de lo que podríamos imaginar, tanto en la ciudad como en el campo, aunque en defensa de las madres habría que recordar que se hacía para proteger una honra mal entendida ${ }^{29}$. En la Varia fortuna se relatan los amores de Anselmo y Estela, donde un bebé recién nacido es el centro, o cuando menos el principio, de la trama. La acción comediesca, que arranca con la entrega del niño a un desconocido, aprovechando el abrigo de la noche, rememora el inicio de La señora Cornelia de

${ }^{28}$ En el Siglo de Oro, esposo y marido no tenían el mismo significado. Esposos eran los que se habían dado palabra de matrimonio. De ahí que ellas tengan esposo, pero no marido, pues aún no se han celebrado las bodas. La ambivalencia de términos venía dada porque, tanto en el derecho civil como en el canónico, tenían el mismo valor jurídico una promesa de casamiento y un enlace de boda. Esta equivalencia fue anulada en el Concilio de Trento, que derogó los matrimonios secretos, por lo cual, la sinonimia legal terminaría siendo sólo semántica. A pesar de la prohibición, el matrimonio secreto es un motivo heredado de los libros de caballerías que tuvo una presencia fecunda en toda la literatura barroca.

29 "El temor a perder la honra podía llevar al abandono nocturno en pleno arroyo, lo cual quizá dé motivo a la frase popular; lo que traía el riesgo de que la criatura muriese comida por puercos, mordida por perros, o simplemente aplastada por cualquier viandante" (M. Fernández Álvarez, La sociedad española en el Renacimiento, Cátedra, Madrid, 1974, p. 120). 
Cervantes ${ }^{30}$. En ambas novelas, se produce de forma similar: por la noche, en secreto y de manera fortuita:

Al fin, echa esta salva, entramos, como dixe, en Ocaña al ponerse la luna, cuya ausencia, aun siendo las tres de la mañana, dexó el lugar con más obscura sombra; pero ni aquesto pudo escusar que no fuéssemos vistos desde una alta ventana, por la qual, al atravesar una calleja angosta, yo, que yva el último, fui llamado con una fácil seña... Díxome: ta villa.

-¡A, cavallero! Suplicoos que paréis y me digáis si sois de aques-

Aquí, reparando la mula, la respondí que no; con que, mostrando más contento, me bolvió a repetir:-Pues de nuevo os suplico que ya que el cielo me á hecho tan dichosa, guiando a este puesto cosa tan conveniente para mi vida y honra, que os sirváis de atenderme (Varia fortuna, t. 2, p. 110).

Era la noche entre escura, y la hora, las once... al pasar por una calle que tenía portales sustentados en mármol oyó que de una puerta le ceceaban. La escuridad de la noche y la que causaban los portales no le dejaban atinar el ceceo. Detúvose un poco, estuvo atento y vio entreabrir una puerta. Llegóse a ella, y oyó una voz baja que dijo:

-¿Sois por ventura Fabio?

Don Juan, por sí o por no, respondió: -Sí.

-Pues, tomad -respondieron de dentro-, y ponedlo en cobro, y volved luego, que importa (Novelas ejemplares, pp. 483-484).

La primera reacción también es la misma en ambos relatos: ellos no sólo colaboran, encubriendo el entuerto, sino que buscan inmediatamente una nodriza que pueda amamantar a la criatura. Por tanto, recurren a la señora más cercana de mayor edad -huéspeda (Varia fortuna)/ama (La señora Cornelia) - para que les ayude en su nueva tarea:

Assí, valiéndome de la piedad y lástima de su género, tomé a la güéspeda por instrumento que le facilitasse, y con ser a desora, halló en ella tanta acogida mi justa pretensión, que sin maior consulta se levantó del lecho, y animada con mis ofrecimientos y promessas, buscó y truxo muger que dentro de mi quadra paladeasse y diesse de mamar a la criatura (Varia fortuna, t. 2, pp. 111-112).

-Menester es -dijo don Juan- dar de mamar a este niño, y ha de ser desta manera: que vos, ama, le habéis de quitar estas ricas mantillas y ponerle otras más humildes, y sin decir que yo le he traído la habéis de llevar en casa de una partera, que las tales siempre suelen dar recado y remedio a semejantes necesidades. Llevaréis dineros con que la dejéis

\footnotetext{
${ }^{30}$ Ya Arsenio Pacheco en su introd. a la Varia fortuna señalaba el notable parecido entre la historia de Anselmo y Estela y la novela cervantina (t. 1, p. cviii, n. 99).
} 
satisfecha y daréisle los padres que quisiéredes, para encubrir la verdad de haberlo yo traído (Novelas ejemplares, pp. 484-485).

El desarrollo a posteriori de la acción es de conocimiento público. La compleja trama novelesca de engaños, recelos y matrimonios secretos tiene un final feliz para unos y otros: una boda santificada por las familias, como por cierto demandaba el teatro comercial del siglo XVII ${ }^{31}$. De hecho, es la única de las cuatro historias de amor en la Varia fortuna que tiene un desenlace afortunado. No habría que olvidar que los niveles de estructura tanto de la historia de Anselmo y Elvira como de La señora Cornelia se mueven dentro de los parámetros de la comedia barroca ${ }^{32}$-amén de la novella italiana, por supuesto.

\section{Conclusiones}

En suma, en la Varia fortuna del soldado Píndaro existe una clara voluntad por parte de Céspedes y Meneses por continuar el modelo narrativo cervantino. En las novelas del talaverano se advierte una larga experiencia en las cosas modernas y una lectura continua de las antiguas, que diría Maquiavelo. Sin despreciar el ascendente del hidalgo de la Mancha, en particular las Novelas ejemplares han demostrado ser una fuente fundamental para entender la estructura interna planteada. Seducido por las maniobras experimentales que Cervantes puso en marcha en su colección de relatos breves y que acabaría perfeccionando en El Quijote de 1615, Céspedes y Meneses escribió una novela fuera de toda catalogación, como ya hiciera aquél, recogiendo por aquí y sembrando por allá las características más adecuadas para el sistema literario desarrollado en torno a Píndaro. Rasgos que le fueron brindando los géneros en boga a principios del siglo XVII: teatro comercial, narrativa bizantina y novella italiana, principalmente. En el supuesto autobiografismo que parece regir la Varia fortuna-supuesto porque nos resulta evidente la inclusión de episodios ficticios- ${ }^{33}$, lo que en realidad trasluce es una lucha dialéctica del individuo con la

${ }^{31}$ La cadena de influencias parece correr en ambas direcciones, pues F. DE Armas ha probado que algunos episodios de la Varia fortuna inspiraron a Calderón de la Barca para La dama duende (“Céspedes y Meneses and Calderón's La dama duende", RNo, 11, 1970, 598-603) o Tirso de Molina para En Madrid y en una casa ("En Madrid y en una casa: un palimpsesto de amantes invisibles", en Actas del IX Congreso Internacional de Hispanistas [Berlín, 18-23 de agosto de 1986], coord. S. Neumeister, 1989, pp. 341-351).

${ }^{32}$ A. GASPARETTi advirtió hace tiempo de que el argumento de La señora Cornelia avanzaba paralelo a la comedia El mayordomo de la duquesa de Amalfi de Lope de Vega (“Giovan Battista Giraldi e Lope de Vega", BHi, 32, 1930, 372-403).

33 "...se non vissuti praticamente, almeno intensamente pensati o desiderati" (J. . RUGGieri, "Gonzalo de Céspedes y Meneses, narratore", Anales de la Universidad de Murcia. Filosofía y Letras, 17, 1958-59, 33-87). 
sociedad, entre unos sueños juveniles y una realidad descarnada, que a través del "querer ser" del protagonista - ¿el propio autor?- busca su lugar en el mundo, como ya lo intentaran los héroes cervantinos. El choque se produce entre una verdad universal, que parece no llegar nunca, y una verdad particular, que genera frustración o sufrimiento. No hay victoria ni fracaso porque el discurso no se construye contra nada o nadie en particular, sino sobre la misma individualidad del personaje. Como metáfora de la vida, el camino que recorre Píndaro desde que abandona el hogar familiar hasta llegar a Bruselas es un proceso de maduración guiado sólo por sus propias decisiones, acertadas o fallidas.

Toda obra humana tiene un propósito y la Varia fortuna no es una excepción. Mirando de reojo a Cervantes, el talaverano renueva el lenguaje de la novela, en busca de la tan ansiada originalidad. Céspedes y Meneses es consciente de que el modelo está abierto. El Quijote ya se encargó de romper moldes. El escritor ya no interioriza los parámetros de un género en particular, sino que absorbe todo aquello que le resulta útil para la consecución de su escritura. Por consiguiente, es difícil clasificar a nuestro Píndaro, si no imposible, por la recreación de una experiencia vital, tal y como demanda hoy en día la novela moderna, que va más allá de una taxonomía de género.

A pesar de ser una autobiografía puesta en duda -al menos, de manera parcial-, no podemos pasar por alto el esfuerzo que hizo para que creyésemos hasta el último de los episodios. Sin credibilidad, toda biografía se derrumba, así que era imperativo conseguir la complicidad del lector. En las Novelas ejemplares, había aprendido de la imposibilidad del texto para valerse por sí mismo. La constatación de qué hace o no referencia a la realidad atañe al que lee y sólo a él. En concreto, en El casamiento engañoso se ilustró en la manera de eliminar cualquier intromisión autorial que rompiera una deseada comunión entre el lector y el texto literario. Como ya aconteciera con el licenciado Peralta, que se quedó leyendo en silencio el coloquio de Cipión y Berganza, el "autor-narrador" promete hacer lo mismo con los legajos que le entrega el soldado Píndaro, donde nos cuenta su vida. Sólo así, convirtiendo todo en un único acto de lectura, se consigue manipular nuestro raciocinio. Al crearse un nuevo marco sin intermediarios, lector y "autor-narrador" disfrutan de la misma experiencia, pues se trata de un solo texto, lo que posibilita que los juicios o sensaciones de uno pasen al otro y ahí es donde el escritor puede inclinar nuestra voluntad a su antojo.

La influencia de las Novelas ejemplares, que estas páginas vienen a demostrar que Céspedes y Meneses las manejaba como libro de cabecera, no acaba aquí. La huella de Las dos doncellas se advierte con facilidad en el comienzo del capítulo 19 de la Varia fortuna, donde un misterioso llanto en la noche despierta la curiosidad de nuestro 
soldado y da pie a una nueva aventura. En ambos casos, la consecución de la trama es la misma, aunque el desenlace distinto: el final feliz cervantino se corresponde con el triste cierre de los amores de doña Elvira, que acaba sus días en un convento. Por último, otro hilo argumental que tiene su origen en la colección de relatos cervantinos es la historia de Anselmo y Elvira, que comienza con la entrega de un recién nacido al primer transeúnte que pasa por la puerta, tal y como sucede en La señora Cornelia. Según se desarrolla la trama, el tratamiento de este motivo es el mismo en ambos escritores: al amparo de la noche, en secreto y de manera accidental. A pesar de la sorpresa de verse con un niño en los brazos, los extraños -que resultan ser nuestros protagonistas, por supuesto- no sólo encubren a la criatura, sino que se involucran en la resolución del caso, que ahora sí tendrá un final feliz para todas las partes, tanto en Cervantes como en Céspedes y Meneses.

Por lo tanto, podríamos afirmar con cierta seguridad que el escritor talaverano no sólo leyó las Novelas ejemplares, sino que se valió de ellas para la composición de la estructura general de su Varia fortuna del soldado Píndaro, así como para el arranque de más de una de las historias o episodios que se entrecruzan en el viaje de nuestro héroe. Una prueba más de lo abrumador que fue el éxito cervantino y la recepción inmediata que tuvieron las Novelas ejemplares, ya imitadas al poco tiempo de fallecer su autor. 